\title{
Food consumption changes and responses to price in the urban areas of Chinese Loess Plateau
}

\author{
Zhiyuan $\mathrm{Xu}^{1,2, \mathrm{a}}$, Changhe $\mathrm{Lu}^{1,2, \mathrm{~b}}$ \\ ${ }^{1}$ Key Laboratory of Land Surface Pattern and Simulation, Institute of Geographical Sciences and \\ Natural Resources Research, CAS, Beijing, 100101, China \\ 2University of Chinese Academy of Sciences, Beijing, 100049, China \\ axuzy.12b@igsnrr.ac.cn, bluch@igsnrr.ac.cn
}

\begin{abstract}
Keywords: the Loess Plateau, urban residents, food consumption, AIDS model
Abstract. This paper applied the AIDS model, using parameter estimation method to estimate the expenditure elasticity, self-price elasticity and cross-price elasticity of the food consumption of urban residents in the Loess Plateau, China. The results showed: the expenditure elasticity of eggs is 3.0268 , which means that it is the elastic good, and grain has the minimum price elasticity, by reason of grain is a kind of goods that lack of flexibility. The variation trend of self-price elasticity is that the elasticity change of grain and oil is not obvious, eggs, meat and poultry's elasticity reduced significantly, indicating that with the development of regional economy and the increase of income, urban residents' sensitivity to price changes for poultry and eggs decreased in the Loess Plateau.
\end{abstract}

\section{Introduction}

Due to the complex geomorphic features, the Loess Plateau has long been a serious problem of soil erosion and fragile ecological environment, where is the key area of ecological construction in China. Since the implementation of Grain to Green Project in 1999, the land use, food production and farmers' livelihood in the region had undergone profound changes [1,2,3]. On the one hand, vegetation restoration and environmental improvement provide a good foundation for crop cultivation, on the other hand, it also has an impact on the food production pattern [4]. Production and consumption are closely related, and the changes of food production in the Loess Plateau after the Grain to Green Project should inevitably lead to the changes of food consumption of the residents in this region. At the same time, income level, price changes, family size and other socio-economic and cultural factors also affect food consumption [5,6]. Chinese scholars are mainly based on national and provincial perspective on food consumption research $[7,8]$, the study of regional scale is relatively few. Based on the analysis of the food consumption changes of urban residents in the Loess Plateau, this paper studied the food elasticity of urban residents by using the classical AIDS model, discussed the regularity of food consumption in Loess Plateau, and provided the basis for optimizing the regional food consumption structure.

\section{Data and methods}

Data Sources and Processing. The data include: the number of major agricultural products purchased per capita by the urban households in the Loess Plateau region in 2000, 2004, 2008 and 2012; the data of disposable income, per capita food expenditure, food price index and per capita food consumption of the major provinces and districts of the Loess Plateau in 2000-2012. The data are mainly from 2001, 2005, 2009 and 2013 statistics yearbook of prefecture-level cities in the Loess Plateau.

To ensure the unity and comparability of data, food consumption data were consolidated into raw grains. For animal foods, food consumption statistics were first calibrated and then converted to raw grains based on the food conversion rates of the different animal foods [9].

AIDS model. The core of the AIDS (Almost Ideal Demand System ) model is to minimize the expense of the consumer at a given price and utility level. The advantage of this model is that relative data are used to reduce the formation of statistical errors. The model can estimate the elasticity of 
demand by estimating almost all the parameters related to the consumption structure and show the impact of various variables on food consumption directly and accurately AIDS [10]. In this paper, AIDS model was used to estimate the food consumption and price elasticity of urban residents in the Loess Plateau. The expression is [11] :

$$
\omega_{i t}=\alpha_{i}+\sum_{j=1}^{n} \gamma_{i j} \log p_{j t}+\beta_{i} \log \left(\frac{m_{t}}{p_{t}^{*}}\right)+\mu_{i t}, \quad p_{t}^{*}=\prod_{i=1}^{n} p_{i t}^{\omega_{i t}} .
$$

Where $\omega_{i t}$ is the consumption expenditure of the $i$-th food in year $\mathrm{t}, p_{j t}$ is the price of the $i$-th food in year $t, m_{t}$ is the total expenditure of food consumption, $\mu_{i t}$ is the random disturbance item, $p_{t}^{*}$ is the comprehensive price index of food, used to exclude the impact of price on expenditure. The parameter $\gamma_{i j}$ represents the effect of price changes of $j$ on $\omega_{i t}$ in year $t$, and $\beta_{i}$ represents the marginal propensity to food. The theoretical model requires that the parameters satisfy the requirements of additive, homogeneous and symmetric, that is,

$$
\sum_{i} \alpha_{i}=1, \quad \sum_{i} \gamma_{i j}=0, \quad \sum_{i} \beta_{i}=0, \quad \sum_{j} \gamma_{i j}=0, \quad \gamma_{i j}=\gamma_{j i}, \quad i \neq j
$$

The Marshall (non-compensatory) price elasticity and expenditure elasticity of each food type can be expressed as follows:

$$
\varepsilon_{i j}^{M}=-\delta_{i j}+\frac{\gamma_{i j}}{\omega_{i}}-\left(\frac{\beta_{i}}{\omega_{i}}\right) \omega_{j}, \eta_{i}=1+\frac{\beta_{i}}{\omega_{i}} .
$$

Where $\delta_{i j}$ is the Kronecker sign, when $i \neq j$, its value is 0 , when $i=j$, its value is 1 . According to Eq. 3 , if the value of $\beta_{i}$ is significantly positive, it means that residents' demand for food $i$ is very flexible; on the contrary, if the value of $\beta_{i}$ is significantly negative, it means that residents' demand for food $i$ is lack of flexibility. When the value of $\beta_{i}$ and $\gamma_{i j}$ are not significant, then the residents' demand for food $i$ has unit price elasticity. In addition, the Hicks (compensatory) price elasticity coefficient can be obtained by the Slutsky equation:

$$
\varepsilon_{i j}^{H}=\varepsilon_{i j}^{M}+\omega_{j} \eta_{i} .
$$

\section{Results}

Changes in food consumption. From 2000 to 2012, the per capita annual food consumption of urban residents in the Loess Plateau is between 292.29 and $315.09 \mathrm{~kg}$, and the annual fluctuation is not significant. Among them, the per capita grain consumption decreased from $148.87 \mathrm{~kg}$ to $124.35 \mathrm{~kg}$, decreased by $24.51 \mathrm{~kg}$, per capita oil consumption increased from $46.67 \mathrm{~kg}$ to $57.90 \mathrm{~kg}$, pork and red meat consumption are relatively stable, turned out between 47.06-52.38 and 19.24-22.43 respectively. Per capita consumption of poultry increased from $11.57 \mathrm{~kg}$ to $16.77 \mathrm{~kg}$. The consumption structure of the seven major food categories of urban residents in the Loess Plateau of 2012 - grain, oil, pork\&red meat, poultry, eggs, aquatic products and milk was 39.96: 18.61: 23.49: $5.39: 7.48: 1.65: 3.43$, and the ratio of plant food and animal food was 41.43: 58.57 (Fig. 1).

Model parameter estimation. Based on the data availability, this paper applied STATA12.0 software and input the data of per capita consumption expenditure, the price index (based on 1999) and food comprehensive price index of various food types from 2000 to 2012 into the AIDS model, and carried out the parameter estimation of food consumption of urban residents in the Loess Plateau. Since food price data are not available, $p_{j t}$ in the model takes the price index for food $j$ in years $t$ instead. In order to avoid the singularity problem of parameter estimation, this model includes only six equations (grain, oil, meat, eggs, aquatic products and milk). The results are shown in Table 1. 


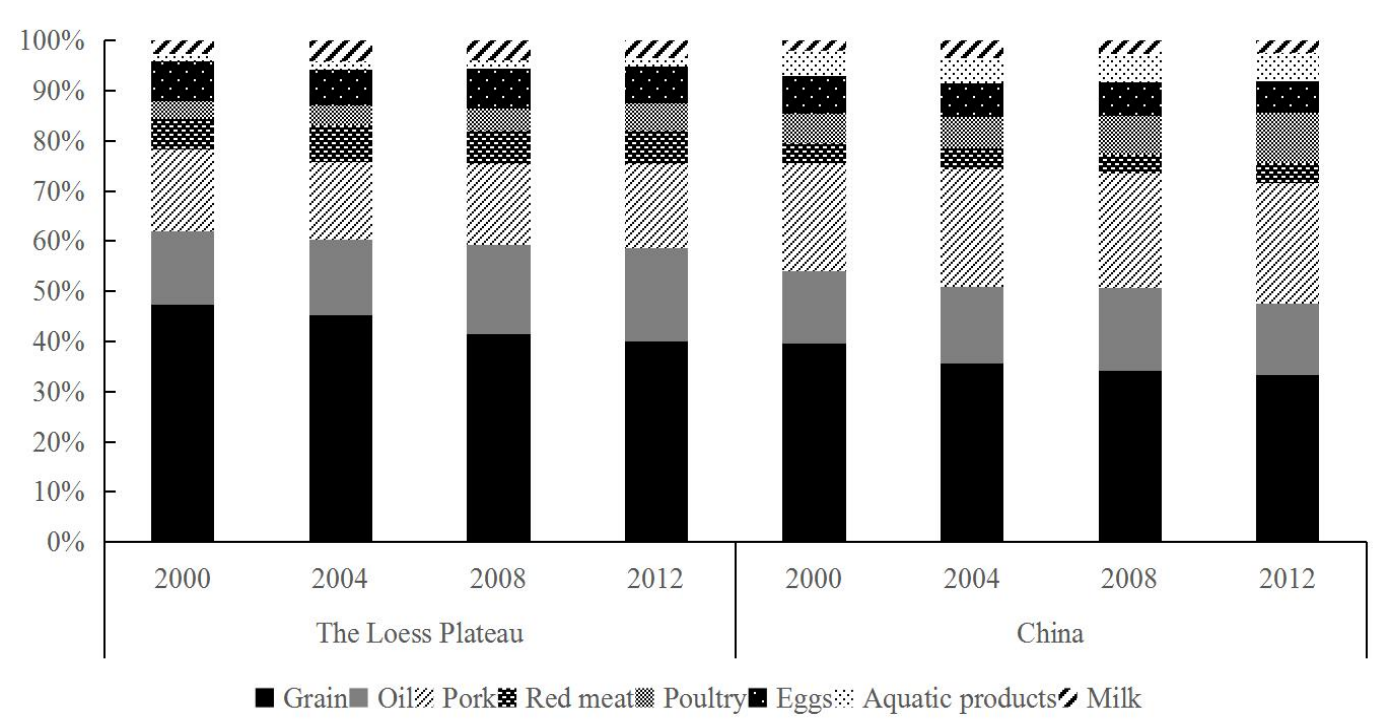

Fig. 1 Changes in food consumption structure of residents in the Loess Plateau

Table 1. The result of model parameter estimation

\begin{tabular}{lcccccc}
\hline & Grain & Oil & Meat & Eggs & Aquatic products & Milk \\
\hline$\gamma_{i 1}$ & -0.0006 & $-0.00174^{*}$ & 0.0015 & -0.0049 & 0.0005 & $0.0054^{* * *}$ \\
& $(-0.45)$ & $(-2.49)$ & -0.79 & $(-1.19)$ & -0.72 & -3.88 \\
$\gamma_{i 2}$ & 0.0001 & $0.00244^{*}$ & 0.0015 & 0.0017 & -0.0008 & $-0.0056^{* *}$ \\
& -0.04 & -2.27 & -0.97 & -0.53 & $(-0.79)$ & $(-2.92)$ \\
$\gamma_{i 3}$ & -0.0007 & $-0.00279^{*}$ & -0.0027 & 0.0000 & 0.0009 & $0.0063^{*}$ \\
& $(-0.51)$ & $(-2.11)$ & $(-1.75)$ & -0.01 & -0.73 & -2.71 \\
$\gamma_{i 4}$ & 0.0004 & 0.0029 & 0.0010 & 0.0039 & -0.0011 & $-0.0087^{* *}$ \\
& -0.29 & -1.91 & -0.77 & -1.54 & $(-0.78)$ & $(-3.28)$ \\
$\gamma_{i 5}$ & 0.0018 & -0.0016 & 0.0006 & -0.0074 & 0.0010 & $0.0068^{*}$ \\
& -0.94 & $(-1.20)$ & -0.25 & $(-1.32)$ & -0.83 & -2.72 \\
$\gamma_{i 6}$ & -0.0010 & 0.0008 & -0.0019 & 0.0066 & -0.0005 & $-0.0042^{* *}$ \\
& $(-0.80)$ & -1.18 & $(-1.10)$ & -1.7 & $(-0.86)$ & $-(-3.18)$ \\
$\beta_{i}$ & $-0.124^{* * *}$ & $-0.0265^{*}$ & -0.0537 & $0.263^{* *}$ & -0.0116 & -0.0471 \\
& $(-4.33)$ & $(-2.42)$ & $(-1.28)$ & -2.79 & $(-1.04)$ & $(-1.90)$ \\
$\mathrm{R}^{2}$ & 0.6528 & 0.8193 & 0.4538 & 0.5451 & 0.1227 & 0.5721 \\
\hline \multicolumn{7}{c}{ Breusch-Pagan检验值: $72.970^{* * *}$} \\
\hline
\end{tabular}

$t$ statistics in parentheses

${ }^{*} p<0.05,{ }^{* *} p<0.01,{ }^{* * *} p<0.001$

The model has a Breusch-Pagan test value of 72.970 and a $p$ value less than 0.001 , indicating that the model rejects the null hypothesis that all the random disturbance terms are irrelevant at the significance level of $0.1 \%$, that is, the conclusion of the model supports the hypothesis of relevance of food demand of urban residents. The model satisfies the homogeneity and additivity constraints, but does not satisfy the symmetry constraint. Not all cross-price parameter estimates must satisfy the symmetry constraint [12], and this result suggests that there may be other factors, such as social customs, that have an impact on food demand. In addition to the low $\mathrm{R}^{2}$ of aquatic products, the other food types of goodness of fit are high, that means the model is generally suitable for the Loess Plateau food consumption research.

In the six categories of food consumption of urban residents in the Loess Plateau, the $\beta_{\text {i value of }}$ eggs was significantly positive, indicating that eggs have a high demand elasticity; the $\beta_{\text {i value of }}$ grain and oil were negative, indicating that there is a lack of expenditure elasticity in the demand for these two types of food; The value of $\beta_{\mathrm{i}}$ and $\gamma_{\mathrm{ij}}$ of aquatic products, meat and poultry is not significant, it means that the urban residents' demand of these two types of food has unit price elasticity.

Food expenditure elasticity and price elasticity of urban residents. The price elasticity of food consumption demand includes self-price elasticity and cross-price elasticity. Since self-price 
elasticity indicates the degree of the consumer's response to a certain type of food for a certain period of time, cross-price elasticity reflects the change of a certain food's demand for other food types' price changes in the degree of response. This paper calculates the self-price elasticity and cross-price elasticity of urban residents' food consumption in the Loess Plateau, and divides them into two types: non-compensatory price elasticity and compensatory price elasticity. Among them, the non-compensatory price elasticity (Marshall price elasticity) does not exclude the impact of price changes on the income of residents and the compensatory price elasticity (Hicks price elasticity) precludes the effect of price changes.

Table 2. Food expenditure elasticity and price elasticity of urban residents

\begin{tabular}{|c|c|c|c|c|c|c|c|}
\hline & & Grain & Oil & Meat & Eggs & $\begin{array}{l}\text { Aquatic } \\
\text { products }\end{array}$ & Milk \\
\hline $\begin{array}{l}\text { expenditure } \\
\text { elasticity }\end{array}$ & & 0.5787 & 0.6160 & 0.8305 & 3.0268 & 0.7184 & 0.6839 \\
\hline \multirow{6}{*}{$\begin{array}{l}\text { Marshall price } \\
\text { elasticity }\end{array}$} & Grain & -0.8779 & 0.0878 & 0.0545 & -0.6342 & 0.0950 & 0.1293 \\
\hline & Oil & 0.0292 & -0.9381 & 0.0163 & -0.1265 & 0.0005 & -0.0158 \\
\hline & Meat & 0.1311 & 0.0812 & -0.9547 & -0.6417 & 0.1105 & 0.1423 \\
\hline & Eggs & 0.0560 & 0.0090 & -0.3708 & -1.6819 & -0.3254 & 1.6060 \\
\hline & $\begin{array}{l}\text { Aquatic } \\
\text { products }\end{array}$ & 0.0234 & -0.0075 & 0.0089 & -0.1408 & -0.9634 & 0.0585 \\
\hline & Milk & 0.0595 & 0.0684 & 0.0192 & -0.2509 & 0.0289 & -0.9810 \\
\hline \multirow{6}{*}{$\begin{array}{l}\text { Hicks price } \\
\text { elasticity }\end{array}$} & Grain & -0.7076 & 0.2691 & 0.2989 & 0.2566 & 0.3064 & 0.3306 \\
\hline & Oil & 0.0692 & -0.8956 & 0.0736 & 0.0824 & 0.0500 & 0.0314 \\
\hline & Meat & 0.3144 & 0.2763 & -0.6916 & 0.3170 & 0.3380 & 0.3589 \\
\hline & Eggs & 0.1311 & 0.0890 & -0.2631 & -1.2891 & -0.2322 & 1.6947 \\
\hline & $\begin{array}{l}\text { Aquatic } \\
\text { products }\end{array}$ & 0.0472 & 0.0179 & 0.0432 & -0.0161 & -0.9338 & 0.0867 \\
\hline & Milk & 0.1457 & 0.1601 & 0.1430 & 0.2001 & 0.1359 & -0.8791 \\
\hline
\end{tabular}

Table 2 presents the food expenditure elasticity and price elasticity of urban residents in the Loess Plateau. The expenditure elasticity of six categories of food are positive. The expenditure elasticity of eggs are 3.0268, indicating that eggs are elastic goods, the expenditure elasticity of other food types are less than 1, that is, they are lack of elasticity. Expenditure elasticity of meat is 0.8305 , which means that meat consumption with a certain expenditure elasticity compared to other food types. In addition, the self-price elasticity of all kinds of food are negative, indicating that the food demand of urban residents in the Loess Plateau changes in the opposite direction of price changes. In the case of non-compensatory price elasticity, the absolute value of self-price elasticity of eggs is the largest and the value is greater than 1, that is to say, urban residents in the Loess Plateau region are sensitive to changes in egg prices, while the absolute values of non-compensatory price elasticity of the other five categories of foods are all less than 1 and grain get the minimum value, which means that the urban residents of Loess Plateau region are least sensitive to the price change of grain, which is related to the rigid demand of grain. The non-compensatory price elasticity of oil, meat, aquatic products and milk are $0.9381,0.9547,0.9634$ and 0.9810 , respectively.

In terms of compensatory price elasticity, the sum of cross price elasticity of milk column is greater than 1, in which the price of milk has a great effect on the price of eggs, and the sum of cross price of grain, meat and eggs rows are all greater than 1, indicating that price changes of other food types have a great impact on the price of these three types of food.

In order to explore the dynamic changes of food price elasticity in the Loess Plateau, this paper calculated the food consumption expenditure elasticity and the compensatory price elasticity of urban residents during 2000-2004, 2005-2008 and 2009-2012 (Table 3). The results show that the expenditure elasticity of grain and oil are relatively stable, the value of meat and aquatic products and milk have been increased, and the expenditure elasticity of eggs growth rapidly. The changes of self-price elasticity of grain and oil are not obvious, and the values of meat, eggs and aquatic products 
are decreasing gradually. This result shows that with the development of regional economy and the increase of residents' income in the Loess Plateau, the sensitivity of the urban residents to the price changes of these food types is gradually reduced, among which the reduction of eggs and meat are the largest.

Table 3. Dynamic changes of food price elasticity in the Loess Plateau

\begin{tabular}{llllllll}
\hline & Year & Grain & Oil & Meat & Eggs & Aquatic products & Milk \\
\hline $\begin{array}{l}\text { Expenditure } \\
\text { elasticity }\end{array}$ & $2000-2004$ & 0.5637 & 0.6218 & 0.8054 & 2.2376 & 0.6916 & 0.6064 \\
& & & & & & & \\
& $2005-2008$ & 0.5911 & 0.6073 & 0.8365 & 4.1276 & 0.7160 & 0.7322 \\
& $2009-2012$ & 0.5840 & 0.6171 & 0.8491 & 4.6524 & 0.7479 & 0.7033 \\
\hline Self-price elasticity & $2000-2004$ & -0.7177 & -0.8951 & -0.7337 & -1.5886 & -0.9350 & -0.9153 \\
& $2005-2008$ & -0.6986 & -0.8964 & -0.6796 & -1.1182 & -0.9339 & -0.8479 \\
& $2009-2012$ & -0.7038 & -0.8955 & -0.6515 & -1.0465 & -0.9316 & -0.8676 \\
\hline
\end{tabular}

\section{Conclusions}

In this paper, food consumption of urban residents in the Loess Plateau were analyzed. Food consumption of urban residents in the Loess Plateau is relatively stable and grain consumption decreased significantly. The prominent feature of animal food consumption is that the consumption proportions of red meat and milk are relatively high, and that of aquatic products are relatively low. The change of food consumption is a concentrated reflection of many factors such as economic development, urbanization, income, food price and so on. In order to explore the trend of food consumption of urban residents in the Loess Plateau, this paper applied AIDS model to calculate the expenditure elasticity and price elasticity. Urban residents in the Loess Plateau region are sensitive to changes in egg prices, and least sensitive to the price change of grain. With the development of regional economy and the increase of income, resident's sensitivity to the price changes of all these food types is gradually reduced, especially eggs and meat.

\section{Acknowledgements}

This work was financially supported by the National Basic Research Program of China (2012CB955304) and the Junior Fellowship for CAST Advanced Innovation Think-tank Program of China Association for Science and Technology (No.DXB-ZKQN-2016-033).

\section{References}

[1] Q. Tang, Y. Xu and Y. Liu: Journal of Arid Land Resources and Environment Vol. 24 (2010), p. 15

[2] Z. Liu and B. Li: Transactions of the Chinese Society of Agricultural Engineering Vol. 11 (2012), p. 1

[3] B. Wang, G. Liu, G. Zhang, Y. Yang: Bulletin of Soil and Water Conservation Vol. 3 (2013), p. 241

[4] Y. Tian, J. Li and Z. Ren: Journal of Arid Land Resources and Environment Vol. 2 (2012), p. 94

[5] Y. Wang: Food and Nutrition in China Vol. 11 (2012), p. 45

[6] H. Tong, F. Liang and Q. Lu: Research of Agricultural Modernization Vol. 6 (2015), p. 996

[7] J. Wu, P. Jiang, X. Huang, Z. Peng and Z. Wang: Journal of Natural Resources Vol. 2 (2013), p. 253

[8] Y. Wang: Food and Nutrition in China Vol. 1 (2015), p. 42

[9] L. Xin, J. Wang and L. Wang: Resources Science Vol. 7 (2015), p.1347

[10] Y. Zhang, W. Yu and Z. Li: Journal of Agro-Forestry Economics and Management Vol. 2 (2012), p. 7

[11] Deaton, A. and J. Muellbauer (1980). An Almost Ideal Demand System. 70: 312-326.

[12] T. Liu, S. Ye and Z. Liu: China Market Vol. 21 (2015), p. 121 